\title{
But-2-ene-1,4-diamine and But-2-ene-1,4-diol as Donors for Thermodynamically Favored Transaminase and Alcohol Dehydrogenase-Catalyzed Processes
}

\author{
Lía Martínez-Montero, ${ }^{\mathrm{a}}$ Vicente Gotor, ${ }^{\mathrm{a}}$ Vicente Gotor-Fernández, ${ }^{\mathrm{a}, *}$ and Iván \\ Lavandera ${ }^{\mathrm{a}, *}$
}

a Departamento de Química Orgánica e Inorgánica, Instituto Universitario de Biotecnología de Asturias, University of Oviedo, C/Julián Clavería 8, 33006 Oviedo, Spain

Fax: (+34) 985 103446; phone: (+34) 985103454 (V.G.-F.) and (+34) 985103452 (I.L.); e-mail: vicgotfer@ uniovi.es (V.G.-F.) and lavanderaivan@uniovi.es (I.L.)

Received: ((will be filled in by the editorial staff))

Supporting information for this article is available on the WWW under http://dx.doi.org/10.1002/adsc.201\#\#\#\#\#\#.

\begin{abstract}
But-2-ene-1,4-diamine have been prepared and efficiently applied as sacrificial cosubstrates in enzymatic transamination reactions. The best results were obtained with the cis-diamine. The thermodynamic equilibrium of the stereoselective transamination process is shifted to the amine formation due to tautomerization of $5 \mathrm{H}$ pyrrole into $1 H$-pyrrole, achieving high conversions (78$99 \%$ ) and enantiomeric excess (up to $>99 \%$ ) by using a small excess of the amine donor. Furthermore, when the reaction proceeded, a strong coloration was observed due to polymerization of $1 H$-pyrrole.
\end{abstract}

A structurally related compound, cis-but-2-ene-1,4-diol, has been utilized as cosubstrate in different alcohol dehydrogenase $(\mathrm{ADH})$-mediated bioreductions. In this case high conversions (91-99\%) were observed due to a lactonization process. Both strategies are convenient from both synthetic and atom economy points of view in the production of valuable optically active products.

Keywords: Alcohol dehydrogenases; atom economy; biocatalysis; cofactor recycling; transaminases

\section{Introduction}

Transaminase (TA)- and alcohol dehydrogenase (ADH)-catalyzed transformations are prominent biocatalytic examples at academic and industrial levels to obtain enantiopure target molecules. ${ }^{[1]}$ Both biocatalyst types can act over carbonylic compounds to accomplish desymmetrization processes (ideally in quantitative yield and selectivity), affording (chiral) amines $^{[2]}$ and alcohols, ${ }^{[3]}$ respectively. Their mechanisms are different, but they have as common feature the necessity of a second molecule (cofactor) to accomplish these transformations. ${ }^{[4]}$ These coenzymes, nicotinamide $[\mathrm{NAD}(\mathrm{P}) \mathrm{H}]$ for $\mathrm{ADHs}$ and pyridoxal 5'-phosphate (PLP) for TAs, must be usually employed in catalytic amounts due to their high costs and inhibition issues. To afford this, excellent cofactor recycling strategies that can overcome the use of stoichiometric quantities of the coenzyme together with a driving of the thermodynamic equilibrium of the process have been described. ${ }^{[5]}$

For ADHs, among the different existing methodologies, the use of a cheap sacrificial alcohol such as 2-propanol has been commonly described in a 'coupled-substrate' approach, generally obtaining excellent results. ${ }^{[6]}$ For TAs, a similar methodology can be successfully applied using an auxiliary amine donor such as isopropylamine. ${ }^{[7]}$ Unfortunately, these cosubstrates must be utilized in a huge molar excess regarding the carbonylic compound to adequately force the reaction into the reduced derivatives. This obviously leads to a poorer atom economy of the process.

Recently, the application of cosubstrates that can greatly reduce the equivalents utilized in biocatalyzed transformations mediated by $\mathrm{ADHs}$ and TAs, is gaining more relevance. Hence, the use of diols such as 1,4-butanediol ${ }^{[8]}$ or 1,6 -hexanediol ${ }^{[9]}$ has allowed 'substrate-coupled' redox processes in close to stoichiometric relation regarding the target substrate. This is due to the thermodynamically favored ring closure of the $\omega$-hydroxyaldehyde intermediate, thus forming the corresponding hemiacetal, which in a subsequent oxidative step renders the final lactone co-product (Scheme 1a). On the other hand, a cyclic amine $^{[10]}$ or a diamine ${ }^{[11]}$ have been described as amine donors that can highly displace the equilibria in TA-catalyzed protocols due to ring aromatization (Scheme 1b). However, the high cost of these tailored amines and difficulties on separating the excess of the donors from the products make interesting the study of other alternatives. 
a)

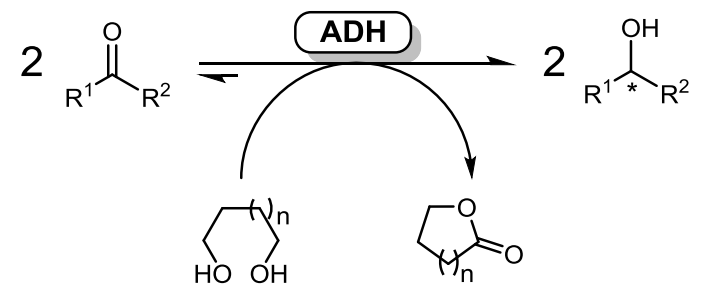

c)

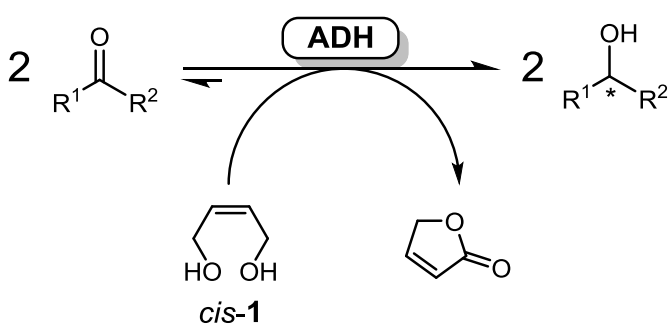

b)

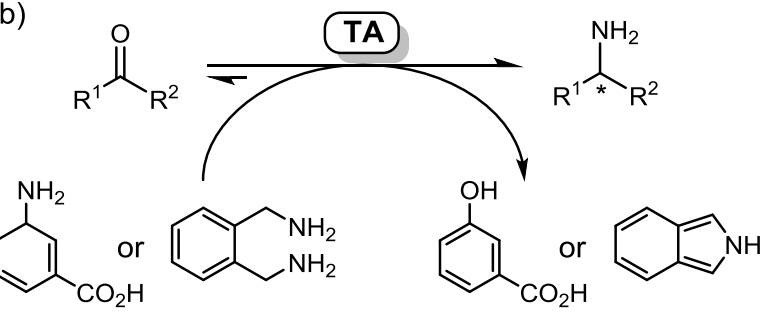

d)

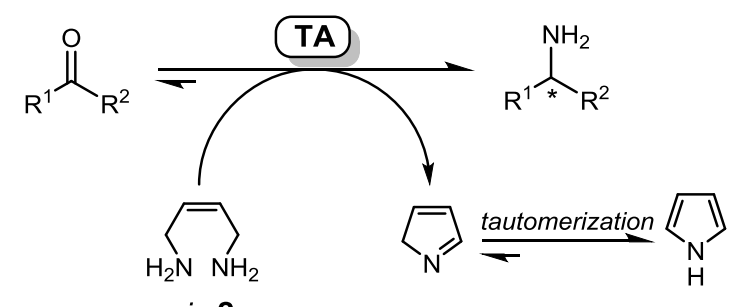

cis-2

Scheme 1. Strategies to drive the thermodynamic equilibria in 'coupled-substrate' approaches: a) ADH-catalyzed reductions via lactonization; b) TA-catalyzed aminations via aromatization; c) and d) ADH- and TA-catalyzed processes using cis-1,4-but-2-ene-diol and cis-1,4-but-2-ene-diamine, respectively (this study).

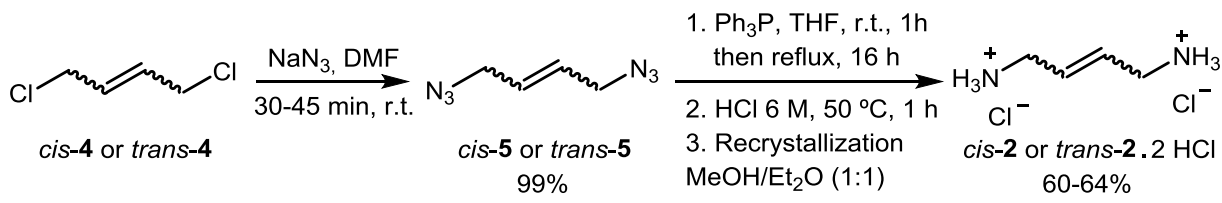

Scheme 2. Synthetic pathway to obtain diamines cis-2 and trans-2.

Herein we have studied the application of two related compounds, cis-but-2-ene-1,4-diol (cis-1) and cisbut-2-ene-1,4-diamine (cis-2), as cosubstrates in $\mathrm{ADH}-$ and TA-mediated transformations, respectively (Schemes 1c and 1d). Thus, after optimization of the reaction conditions, we demonstrate that these derivatives can be employed at much lower extent than conventional cosubstrates to obtain enantioenriched alcohol and amine products through enzyme-catalyzed reactions, with high purity after a simple extraction.

Based on previously described protocols that make use of designed cosubstrates to favor TA-mediated processes, ${ }^{[18,11]}$ we envisaged that simple 1,4diamines could be used for this purpose. Once the $\omega$ aminoaldehyde intermediates were formed, they could intramolecularly cyclize, thus providing the driving force that could transform quantitatively the carbonylic compound of interest. With this in mind, diamines cis-2 and 1,4-butanodiamine $\mathbf{3}$ were envisioned as perfect candidates. Moreover, in the case of $c i s-2$, after cyclization to $5 \mathrm{H}$-pyrrole, it could tautomerize into $1 H$-pyrrole (Scheme 1d).

\section{Results and Discussion}

While diamine $\mathbf{3}$ is commercially available, we synthesized cis-2. As a first approach, we used diol cis-1 as starting material. ${ }^{[12]}$ Different conditions such as Mitsunobu reaction or alcohol activation through $O$-tosylation were tried, but unfortunately these protocols did not work out. Hence, we employed a slightly modified method proposed by Delcros and co-workers, ${ }^{[13]}$ starting from commercially accessible cis-1,4-dichlorobut-2-ene (cis-4, Scheme 2). In a first step both halogen atoms were substituted by azides using a typical nucleophilic substitution protocol, and in a second step the reduction of diazido compound cis-5 was carried out under Staudinger conditions with triphenylphosphine, followed by acidic hydrolysis affording cis-2 as dichlorohydrate salt. During this synthetic pathway an alkene isomerization into the trans-diamine (trans-2) was observed, therefore recrystallization in a methanol/diethyl ether $(1: 1)$ mixture was performed, providing the desired compound with high cis/trans selectivity (approx. 95:5). To check the effect of the double bond stereochemistry, diamine trans-2 was also synthesized following the same reaction route (Scheme 2).

In a first set of experiments, three different ketones (6-8a, see Table 1) were used as suitable substrates with two commercially available transaminases (Figure 1). Thus, a small excess of the amine donor (1.5 equivalents) was applied. Gladly, TAs could accept diamine cis-2 as donor, affording the corresponding amines 6-8b with high to excellent 
conversions after $48 \mathrm{~h}$ at $30^{\circ} \mathrm{C}$. Although in a minor extent, trans-2 could also provide moderate to high conversions, while saturated diamine $\mathbf{3}$ appeared as a poor substrate for these enzymes. These results remark the relevance of the presence and stereochemistry of the double bond in the structure of the diamine, which is the key to provide the ring aromatization.

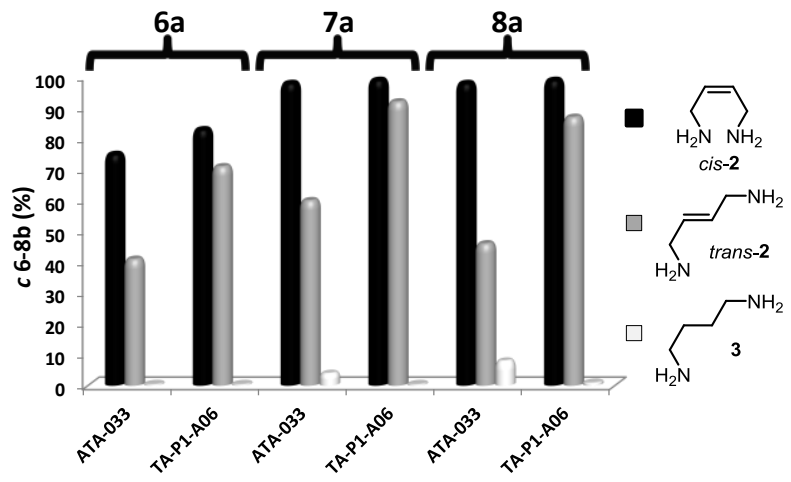

Figure 1. Effect of the amine donor in TA-catalyzed reactions using 1.5 equiv. of cis-2, trans-2, and $\mathbf{3}$.

Interestingly, when the reaction proceeded with cis-2 and trans-2, it was observed the formation of black colored precipitates. This can be ascribed to the polymerization of the pyrrole by-product resulting in the formation of polypyrrole. ${ }^{[14]}$ In fact, when we incubated pyrrole in the reaction medium in the absence of enzyme and PLP, we did not observe coloration, but when we accomplished the same experiment just adding PLP, a quick formation of the black polymers was detected. It seems that PLP mediates the polymerization of pyrrole acting as an acidic catalyst. This phenomena is also in agreement with the previously described by Turner and coworkers, ${ }^{[1]}$ where the isoindole co-product (Scheme 1b) polymerized under similar conditions affording intense colored derivatives. As in their case, this observation can potentially lead to a sensitive and operationally simple colorimetric assay to identify TA activity. ${ }^{[1,15]}$

The formation of pyrrole was also demonstrated by NMR experiments performing the enzymatic reactions in deuterium oxide (see SI for more details). Surprisingly, when we studied the transformation using trans-2 as amine donor, it was also observed the presence of pyrrole in the reaction crude. This fact can explain why in the presence of this diamine the aspect of the medium was similar. If pyrrole is formed, at some point there must be a cis/trans isomerization of the double bond, otherwise cyclization would not be possible. When we incubated trans-2 in the reaction medium without any ketone substrate, isomerization was not observed. Therefore, we speculate that the trans- $\omega$ aminoaldehyde intermediate formed after deamination of trans-2 must be the species which undergoes this process (Scheme 3). This is not surprising as it has been described that similar $\alpha, \beta$ unsaturated aldehydes can isomerize in the presence of pyridine derivatives, which can achieve a reversible 1,4-addition. ${ }^{[16]}$ In our case PLP could act as the isomerization agent.

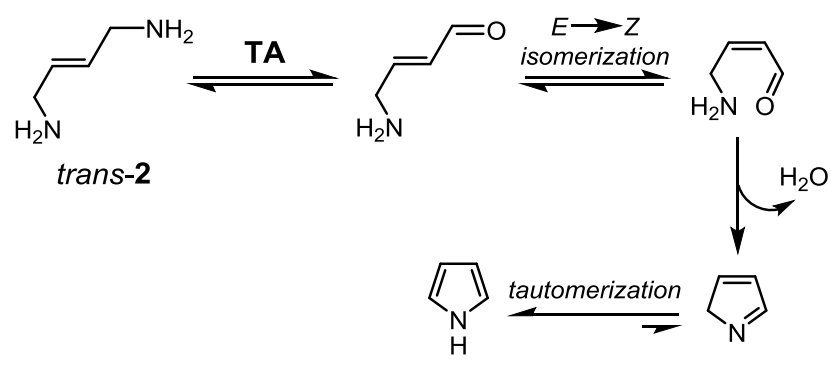

Scheme 3. Transformation of diamine trans-2 into pyrrole through the isomerization of the trans- $\omega$-aminoaldehyde intermediate.

Table 1. Amination of ketones 6-19a using cis-2 (3 equiv.) as amine donor. ${ }^{[\mathrm{a}]}$
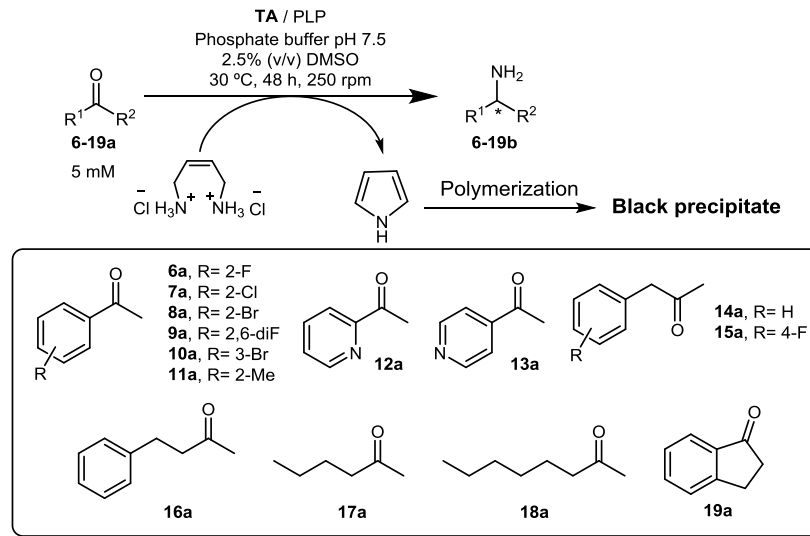

\begin{tabular}{lllll}
\hline Entry & Ketone & Enzyme & $c[\%]^{[\mathrm{b}]}$ & $e e[\%]^{[\mathrm{c}]}$ \\
\hline 1 & $\mathbf{6 a}$ & ATA-033 & 96 & $>99(R)$ \\
2 & $\mathbf{6 a}$ & TA-P1-G06 & 97 & $>99(S)$ \\
3 & $\mathbf{7 a}$ & ATA-033 & 98 & $>99(R)$ \\
4 & $\mathbf{7 a}$ & TA-P1-G06 & 99 & $>99(S)$ \\
5 & $\mathbf{8 a}$ & ATA-025 & 99 & $>99(R)$ \\
6 & $\mathbf{8 a}$ & TA-P1-A06 & 99 & $>99(S)$ \\
7 & $\mathbf{9 a}$ & ATA-012 & 96 & $>99(R)$ \\
8 & $\mathbf{1 0 a}$ & ATA-033 & 79 & $>99(R)$ \\
9 & $\mathbf{1 1 a}$ & ATA-024 & 82 & $>99(R)$ \\
10 & $\mathbf{1 2 a}$ & ATA-025 & 93 & $>99(R)$ \\
11 & $\mathbf{1 2 a}$ & TA-P1-A06 & 93 & $99(R)$ \\
12 & $\mathbf{1 3 a}$ & ATA-033 & 98 & $>99(R)$ \\
13 & $\mathbf{1 4 a}$ & TA-P1-A06 & 78 & $>99(S)$ \\
14 & $\mathbf{1 5 a}$ & TA-P1-A06 & 99 & $92(S)$ \\
15 & $\mathbf{1 6 a}$ & TA-P1-A06 & 92 & $95(S)$ \\
16 & $\mathbf{1 7 a}$ & ATA-113 & 80 & $82(S)$ \\
17 & $\mathbf{1 8 a}$ & TA-P1-A06 & 82 & $88(S)$ \\
18 & $\mathbf{1 9 a}$ & ATA-256 & 89 & $26(S)$ \\
\hline
\end{tabular}

${ }^{[a]}$ For reaction conditions, see SI.

${ }^{[b]}$ Measured by GC analysis.

${ }^{[c]}$ Measured by chiral GC or HPLC analysis. 
Subsequently, cis-2 was applied as amine donor in phosphate buffer and in the presence $(2.5 \% \mathrm{v} / \mathrm{v})$ of dimethylsulfoxide (DMSO) as solubilizing agent with ketones 6-19a (Table 1). This selection was made based on a previous study performed in our group ${ }^{[17]}$ due to the relevance of the obtained amines as precursors of interesting derivatives. ${ }^{[18]}$ Aromatic (entries 1 to 9), heteroaromatic (entries 10 to 12), and aliphatic substrates (entries 13 and 17) could be transformed into the corresponding enantioenriched amines with excellent conversions and enantiomeric excess. Interestingly, TAs with opposite stereopreference can work under these conditions, therefore providing both antipodes for some of the selected examples. ATA-025 and ATA-033 showed the best results in terms of $R$-selectivity, and TA-P1A06 and TA-P1-G06 were in general the best candidates to obtain the $S$-enantiomers. We also carried out a study on a cyclic ketone such as 1indanone (19a, see SI). We were pleased to observe that meanwhile 1-indanone was slightly converted for most of the enzymes tested using isopropylamine as amino donor, in some cases conversions dramatically increased using cis-2 to afford the corresponding amine with modest enantiomeric excess (entry 18).

It has been previously described that similar cosubstrates can also favor these processes from a kinetic point of view regarding conventional donors. ${ }^{[8 c]}$ In this case, initial rates of TA-catalyzed reactions using isopropylamine, cis-2, and trans-2 were measured. We found that isopropylamine reacted faster than both diamines (especially than the trans isomer), leading to the highest initial rate (see SI). This fact shows that these transformations are mainly thermodynamically (but not kinetically) driven.

The use of this diamine is particularly advantageous, since after a simple extraction protocol is possible to obtain the desired amines with high purity, as diamine $c i s-\mathbf{2}$ is completely soluble in water and the excess of this compound remains on the aqueous phase even after extraction under basic conditions. Moreover, polymers coming from pyrrole can be easily removed in this case by centrifugation.

As a proof, we applied this transformation concept on a preparative scale. Thus, $100 \mathrm{mg}$ of ketones $7 \mathbf{a}$ and 8a were transformed into the corresponding $(R)$ amines (>99\% ee) using ATA-033 and cis-2 (1.5 equiv.) in $74-83 \%$ yield after $48 \mathrm{~h}$ of reaction.

Finally, we have compared the conventional methodology using an excess of isopropylamine, with thermodynamically favored strategies employed for TA-catalyzed reactions, calculating the theoretical value of waste generated according to the reaction equation. ${ }^{[19]}$ To perform this, we have used the EATOS program, ${ }^{[20]}$ assuming a cosubstrate molar excess as described by the corresponding authors, ${ }^{[10,11]}$ and a quantitative conversion of a model ketone (6a, Table 2). As can be seen, our methodology (entry 4) was perfectly comparable to similar previously described strategies (entries 2 and 3 ), while greatly improving the standard conditions using isopropylamine (entry 1). The method presented here upgrades the previous ones as the coproduct obtained (pyrrole), displays a substantially lower molecular weight.

Table 2. Quantity of waste generated per $\mathrm{kg}$ of amine (6b) synthesized depending on the amine donor. ${ }^{[\mathrm{a}]}$

\begin{tabular}{llll}
\hline Entry & Amine donor & Molar excess $^{[\mathrm{b}]}$ & $\begin{array}{l}\text { Waste (kg } \\
\mathrm{kg}^{-1} \text { product) }\end{array}$ \\
\hline 1 & IPA $^{[\mathrm{c}]}$ & 40 & 17 \\
2 & Cyclic amine $^{[\mathrm{d}]}$ & 1.05 & 1.04 \\
3 & Diamine $^{[\mathrm{e}]}$ & 1.1 & 1.07 \\
4 & cis-2 $^{2}$ & 1.5 & 0.92 \\
\hline
\end{tabular}

Calculated using the EATOS program. Quantitative conversion was assumed.

${ }^{[b]}$ Regarding the ketone substrate.

${ }^{[c]}$ Isopropylamine.

[d] Amine donor described by Berglund and co-workers (see Scheme 1b). ${ }^{[10]}$

${ }^{\text {[e] }}$ Amine donor described by Turner and co-workers (see Scheme 1b). ${ }^{[11]}$

Likewise, diol cis-1, previously tried as synthetic precursor of diamine cis-2, was envisioned as suitable cosubstrate for $\mathrm{ADH}$-mediated bioreductions in a similar way as shown by Hollmann and co-workers with the saturated derivatives. ${ }^{[8,9]}$

After a first enzymatic screening, we observed that horse liver ADH (HLADH) and Thermoanaerobacter sp. ADH (ADH-T) overexpressed in E. coli, were able to accept this diol as hydrogen donor. Then, it was demonstrated that cis-1 can drive the equilibrium into the reduction mode with higher efficiency than the usual donors such as EtOH (for HLADH) or 2$\mathrm{PrOH}$ (for ADH-T), since by simple addition of equimolar or slight excess of the diol, excellent conversions (and $e e$ for 11c, 21c and 22c) into the corresponding alcohols were achieved (Figure 2). The formation of the unsaturated lactone furan-2(5H)-one co-product was confirmed by GC analysis (see SI).

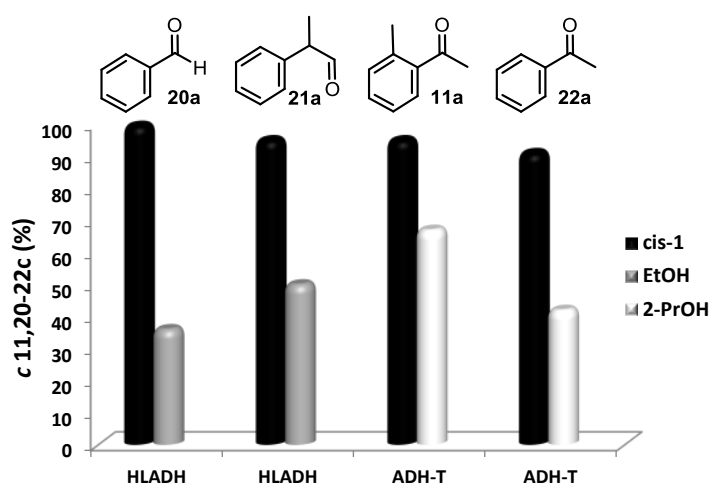

Figure 2. Effect of the hydrogen donor in ADH-catalyzed reactions using 0.5 equiv. (for $\mathrm{HLADH}$ ) or 3 equiv. (for $\mathrm{ADH}-\mathrm{T})$ of cis-1, EtOH (HLADH) and 2-PrOH (ADH-T). 


\section{Conclusions}

Herein we have shown the use of two related compounds, diamine cis-2 and diol cis-1, in order to drive the equilibrium of TA- and ADH-catalyzed processes by using a 'coupled-substrate' approach. A tautomerization of co-product $5 \mathrm{H}$-pyrrole into $1 \mathrm{H}$ pyrrole and a lactonization reaction, respectively, are responsible of the excellent conversions attained using a small excess of these cosubstrates. Furthermore, in the case of the diamine a strong coloration of the enzymatic transformation was observed when the reaction proceeded due to the pyrrole polymerization. The excess of both cosubstrates and co-products formed can be easily removed from the products of interest, making these compounds highly appealing for ADH- and TAcatalyzed transformations, enhancing their possible applications from both synthetic and atom economy points of view. Thus, the amount of waste generated due to the amine donor employed, was comparable with current existing transaminase-catalyzed methods to shift the reaction equilibrium towards the desired product, improving the traditional methodology using an excess of isopropylamine.

\section{Experimental Section}

\section{Synthesis of cis/trans-but-2-ene-1,4-diamine dihydrochloride (cis/trans-2)}

Diazide intermediates cis/trans-5 were afforded from the respective cis/trans-4 using a nucleophilic substitution reaction. Dichlorinated compound cis/trans -4 (4.75 mmol, $0.5 \mathrm{~mL})$ was added to a stirred solution of $\mathrm{NaN}_{3}(42.7$ mmol, $2.77 \mathrm{~g})$ in DMF $(7 \mathrm{~mL})$ and the magnetic stirring was continued until disappearance of the starting material (30-45 $\mathrm{min})$. Then, the reaction was quenched by addition of water $(10 \mathrm{~mL})$ and extracted with EtOAc $(3 \mathrm{x} 15 \mathrm{~mL})$. The organic layer was dried with $\mathrm{Na}_{2} \mathrm{SO}_{4}$, filtered off and concentrated. The residue was purified by flash column chromatography (20\% EtOAc/hexane) on silica gel to remove the DMF still remaining after the extraction, leading to the corresponding diazide compounds cis/trans5 as orange oil in quantitative yields.

Desired diamines were prepared as dihydrochloride salts through the reduction of the previous diazides cis or trans5 and subsequent acidification. To a solution of cis/trans-5 $(4.70 \mathrm{mmol}, 649 \mathrm{mg})$ in dry THF $(9 \mathrm{~mL})$, a solution of $\mathrm{Ph}_{3} \mathrm{P}$ (9.45 mmol, $2.48 \mathrm{~g}$ ) in dry THF (6 mL) was added. This mixture was stirred at room temperature during the first hour. After this time, the reaction mixture was heated at $50{ }^{\circ} \mathrm{C}$ for $16 \mathrm{~h}$. Then, the hydrolysis was carried out by the addition of an aqueous $\mathrm{HCl}$ solution $6 \mathrm{M}(1 \mathrm{~mL})$, maintaining the reaction at $50{ }^{\circ} \mathrm{C}$ during one additional hour. Finally, water $(3 \mathrm{~mL})$ and concentrated $\mathrm{HCl}(500 \mu \mathrm{L})$ were added and THF was removed under vacuo. To the obtained residue, water $(10 \mathrm{~mL})$ was added, and the aqueous layer was extracted with EtOAc $(5 \times 10 \mathrm{~mL})$. The water was removed under reduced pressure $\left(50^{\circ} \mathrm{C}\right)$, affording a brown crude. The brown crude obtained evaporating the aqueous layer, was recrystallized from a mixture of $\mathrm{MeOH}-\mathrm{Et}_{2} \mathrm{O}(\mathrm{v} / \mathrm{v})$, leading to the desired diamine dihydrohloride cis-2 as a white solid (60\% yield), with a small amount of the unwished isomer trans-2, just observed in the ${ }^{1} \mathrm{H}$ NMR spectra (ratio cis/trans: 95:5) or to diamine trans-2 in high purity as a white solid $(64 \%$ yield).
General procedure for enzymatic transamination reactions using $c i s-2$ as amine donor

In a $1.5 \mathrm{~mL}$ Eppendorf vial, substrate 6-19a (5 mM, 12.5 $\mu \mathrm{L}$ from $200 \mathrm{mM}$ stock in DMSO), was dissolved in phosphate buffer $(500 \mu \mathrm{L}, 100 \mathrm{mM}, \mathrm{pH} 7.5)$ containing PLP (2 mM) and cis-2 (7.5 mM, 1.5 equiv. or $15 \mathrm{mM}, 3$ equiv.). Finally the commercially available transaminase (2 $\mathrm{mg}$ ) was added. The initial slightly yellow reaction was shaken at $30{ }^{\circ} \mathrm{C}$ and $250 \mathrm{rpm}$ for $48 \mathrm{~h}$ (observing after this time that the reaction media was completely black with the appearance of a solid at the bottom of the vial), and then stopped by the addition of an aqueous $\mathrm{NaOH}$ solution 10 $\mathrm{M}(250 \mu \mathrm{L})$. Then, the mixture was extracted with EtOAc $(2 \mathrm{x} 0.5 \mathrm{~mL})$, the organic layer was separated by centrifugation (2 min, $13000 \mathrm{rpm}$ ) and dried over $\mathrm{Na}_{2} \mathrm{SO}_{4}$. Conversions were determined by GC and enantiomeric excess by chiral GC or HPLC (see Table 1).

\section{Scaling-up reactions}

In an Erlenmeyer flask (100 mL), ketone 7a or $8 \mathbf{a}(25 \mathrm{mM}$, $0.502 \mathrm{mmol}, 100 \mathrm{mg}$ ) was dissolved in phosphate buffer (100 mM, pH 7.5) containing PLP (2 mM), MeCN (2.5\% $\mathrm{v} / \mathrm{v})$ as organic cosolvent and cis-2 $(37.5 \mathrm{mM}, 1.5$ equiv. as amine donor. Finally, ATA-033 (75 mg) was added. Then, the initial slightly yellowish reaction was shaken at $30{ }^{\circ} \mathrm{C}$ and $250 \mathrm{rpm}$ for $48 \mathrm{~h}$. After that time, the reaction media was completely black. The conversion was determined by taking a sample $(200 \mu \mathrm{L})$ of the reaction mixture which was basified with an aqueous $\mathrm{NaOH}$ solution $10 \mathrm{M}(100 \mu \mathrm{L})$ and extracted as shown above, leading to $78 \%$ and $89 \%$ conversion for $7 \mathbf{a}$ and $\mathbf{8 a}$, respectively (measured by GC). At this point, the solution was centrifuged at $4,900 \mathrm{rpm}$ for $7 \mathrm{~min}$. The supernatant was decanted, acidified with an aqueous $\mathrm{HCl}$ solution $3 \mathrm{M}$ $(5 \mathrm{~mL})$ and extracted with $\mathrm{Et}_{2} \mathrm{O}(3 \times 25 \mathrm{~mL})$ discarding the organic layer, in order to remove the small amount of the starting material. Then, the aqueous phase was basified with an aqueous $\mathrm{NaOH}$ solution $10 \mathrm{M}(8 \mathrm{~mL})$ and extracted with $\mathrm{Et}_{2} \mathrm{O}(3 \times 35 \mathrm{~mL})$. The organic layers were combined, dried over $\mathrm{Na}_{2} \mathrm{SO}_{4}$ and the solvent was evaporated under reduced pressure providing $(R)-7 \mathbf{b}(74 \%$ yield, $>99 \% e e)$ and $(R)-8 b(83 \%$ yield, $>99 \% e e)$.

\section{General procedure for alcohol dehydrogenase-catalyzed} reductions using $c i s$-but-2-ene-1,4-diol (cis-1) as cosubstrate

For E. coli/HLADH: In a $1.5 \mathrm{~mL}$ Eppendorf vial, aldehydes 20a and 21a $(0.022 \mathrm{mmol}, 32 \mathrm{mM})$ were dissolved in phosphate buffer $(700 \mu \mathrm{L}, 50 \mathrm{mM}, \mathrm{pH} 8)$, containing $\mathrm{NADH}(1 \mathrm{mM})$ and cis-1 (0.5 equiv., $16 \mathrm{mM})$ as cosubstrate. Finally $E$. coli/HLADH $(1.5 \mathrm{mg})$ was added. The reaction was shaken at $30^{\circ} \mathrm{C}$ and $250 \mathrm{rpm}$ for $22 \mathrm{~h}$ and extracted with EtOAc $(2 \times 0.5 \mathrm{~mL})$. The organic layer was separated by centrifugation ( $2 \mathrm{~min}, 13000 \mathrm{rpm})$ and dried over $\mathrm{Na}_{2} \mathrm{SO}_{4}$. Conversions and enantiomeric excess (for 21c) were determined by GC and HPLC, respectively (Table S4). The presence of furan-2(5H)-one in the reaction media was confirmed by GC analysis.

For E. coli/ADH-T: In a $1.5 \mathrm{~mL}$ Eppendorf vial, the corresponding ketones 11a and 22a $(0.017 \mathrm{mmol}, 34 \mathrm{mM})$ were dissolved in Tris. $\mathrm{HCl}$ buffer $(500 \mu \mathrm{L}, 50 \mathrm{mM}, \mathrm{pH}$ $7.5)$, containing NADPH (1 mM) and cis-1 (102 mM, 3 equiv.) as cosubstrate. Finally $E$. coli/ADH-T $(15 \mathrm{mg})$ was added. The reaction was shaken at $30{ }^{\circ} \mathrm{C}$ and $250 \mathrm{rpm}$ for $24 \mathrm{~h}$ and extracted with EtOAc $(2 \times 0.5 \mathrm{~mL})$. The organic layer was separated by centrifugation $(2 \mathrm{~min}, 13000 \mathrm{rpm})$ and dried over $\mathrm{Na}_{2} \mathrm{SO}_{4}$. Conversions and enantiomeric excess were determined by GC analysis (Table S5). The presence of furan-2(5H)-one in the reaction media was confirmed by $\mathrm{GC}$ analysis. 


\section{Acknowledgements}

We thank Prof. Martina Pohl (Forschungszentrum Jülich GmbH) and Prof. Wolfgang Kroutil (TU Graz) for the generous donation of HLADH and ADH-T plasmids, respectively. Financial support from MICINN (Project CTQ2013-44153-P) is gratefully acknowledged. L.M.-M. thanks the Principado de Asturias for her predoctoral fellowship Severo Ochoa.

\section{References}

[1] a) J. M. Woodley, Curr. Opin. Chem. Biol. 2013, 17, 310-316; b) U. T. Bornscheuer, G. W. Huisman, R. J. Kazlauskas, S. Lutz, J. C. Moore, K. Robins, Nature 2012, 485, 185-194; c) D. Muñoz Solano, P. Hoyos, M. J. Hernáiz, A. R. Alcántara, J. M. Sánchez-Montero, Bioresour. Technol. 2012, 115, 196-207; d) B. M. Nestl, B. A. Nebel, B. Hauer, Curr. Opin. Chem. Biol. 2011, 15, 187-193.

[2] Recent bibliography on transaminases: a) M. Fuchs, J. E. Farnberger, W. Kroutil, Eur. J. Org. Chem. 2015, 6965-6982; b) R. C. Simon, E. Busto, E.-M. Fischereder, C. S. Fuchs, D. Pressnitz, N. Richter, W. Kroutil in Science of Synthesis, Biocatalysis in Organic Synthesis, (Eds.: K. Faber, W.-D. Fessner, N. J. Turner), Georg Thieme Verlag, Stuttgart, 2015, pp. 383-420; c) R. C. Simon, N. Richter, E. Busto, W. Kroutil, ACS Catal. 2014, 4, 129-143; d) W. Kroutil, E.-M. Fischereder, C. S. Fuchs, H. Lechner, F. G. Mutti, D. Pressnitz, A. Rajagopalan, J. H. Sattler, R. C. Simon, E. Siirola, Org. Process Res. Dev. 2013, 17, 751-759; e) M. Höhne, U. T. Bornscheuer in Enzyme Catalysis in Organic Synthesis, 3rd ed., (Eds.: K. Drauz, H. Gröger, O. May), Wiley-VCH, Weinheim, 2012, pp. 779-820; f) M. S. Malik, E.-S. Park, J.-S. Shin, Appl. Microbiol. Biotechnol. 2012, 94, 1163-1171; g) S. Mathew, H. Yun, ACS Catal. 2012, 2, 993-1001; h) D. Koszelewski, K. Tauber, K. Faber, W. Kroutil, Trends Biotechnol. 2010, 28, 324-332; i) H. C. Hailes, P. A. Dalby, G. J. Lye, F. Baganz, M. Micheletti, N. Szita, J. M. Ward, Curr. Org. Chem. 2010, 14, 1883-1893; j) D. Zhu, L. Hua, Biotechnol. J. 2009, 4, 1420-1431.

[3] Recent bibliography on alcohol dehydrogenases: a) T. S. Moody, S. Mix, G. Brown, D. Beecher in Science of Synthesis, Biocatalysis in Organic Synthesis, (Eds.: K. Faber, W.-D. Fessner, N. J. Turner), Georg Thieme Verlag, Stuttgart, 2015, pp. 421-458; b) Synthetic Methods for Biologically Active Molecules, (Ed.: E. Brenna), Wiley-VCH, Weinheim, 2014; c) H. Gröger, W. Hummel, S. Borchert, M. Kraußer in Enzyme Catalysis in Organic Synthesis, 3rd ed., (Eds.: K. Drauz, H. Gröger, O. May), Wiley-VCH, Weinheim, 2012, pp. 1037-1110; d) M. M. Musa, R. S. Phillips, Catal. Sci. Technol. 2011, 1, 1311-1323; e) E. GarcíaUrdiales, I. Alfonso, V. Gotor, Chem. Rev. 2011, 111, PR110-PR180; f) M. Hall, A. S. Bommarius, Chem. Rev. 2011, 111, 4088-4110; g) F. Hollmann, I. W. C. E. Arends, D. Holtmann, Green Chem. 2011, 13, 2285-2313; h) G. W. Huisman, J. Liang, A. Krebber, Curr. Opin. Chem. Biol. 2010, 14, 122-129.

[4] M. Richter, Nat. Prod. Rep. 2013, 30, 1324-1345.
[5] a) R. Abu, J. Woodley, ChemCatChem 2015, 7, 3094-3105; b) E. E. Ferrandi, D. Monti, S. Riva in Cascade Biocatalysis, (Eds.: S. Riva, W.-D. Fessner), Wiley-VCH, Weinheim, 2014, pp. 23-42; c) S. Kara, J. H. Schrittwieser, F. Hollmann, M. B. AnsorgeSchumacher, Appl. Microb. Biotechnol. 2014, 98, 1517-1529; d) W. Hummel, H. Gröger, J. Biotechnol., 2014, 191, 22-31; e) T. Quinto, V. Köhler, T. R. Ward, Top. Catal. 2014, 57, 321-331; f) H. Wu, C. Tian, X. Song, C. Liu, D. Yang, Z. Jiang, Green Chem. 2013, 15, 1773-1789; g) C. Rodríguez, I. Lavandera, V. Gotor, Curr. Org. Chem. 2012, 16, 2525-2541; h) F. Hollmann, I. W. C. E. Arends, K. Buehler, ChemCatChem 2010, 2, 762-782.

[6]W. Kroutil, H. Mang, K. Edegger, K. Faber, Curr. Opin. Chem. Biol. 2004, 8, 120-126.

[7] K. E. Cassimjee, C. Branneby, V. Abedi, A. Wells, P. Berglund, Chem. Commun. 2010, 46, 5569-5571.

[8] a) R. Zuhse, C. Leggewie, F. Hollmann, S. Kara, Org. Process Res. Dev. 2015, 19, 369-372; b) S. Kara, D. Spickermann, A. Weckbecker, C. Leggewie, I. W. C. E. Arends, F. Hollmann, ChemCatChem 2014, 6, 973976; c) S. Kara, D. Spickermann, J. H. Schrittwieser, C. Leggewie, W. J. H. van Berkel, I. W. C. E. Arends, F. Hollmann, Green Chem. 2013, 15, 330-335.

[9] A. Bornadel, R. Hatti-Kaul, F. Hollmann, S. Kara, ChemCatChem 2015, 7, 2442-2445.

[10] B. Wang, H. Land, P. Berglund, Chem. Commun. 2013, 49, 161-163.

[11] A. P. Green, N. J. Turner, E. O. Reilly, Angew. Chem. 2014, 126, 10890-10893; Angew. Chem. Int. Ed. 2014, 53, 10714-10717.

[12] E. Fabiano, B. T. Golding, M. M. Sadeghi, Synthesis 1987, 190-192.

[13] B. Martin, F. Possémé, C. Le Barbier, F. Carreaux, B. Carboni, N. Seiler, J.-P. Moulinoux, J.-G. Delcros, Bioorg. Med. Chem. 2002, 10, 2863-2871.

[14] T. V. Vernitskaya, O. N. Efimov, Russ. Chem. Rev. 1997, 66, 443-457.

[15] D. Baud, N. Ladkau, T. S. Moody, J. M. Ward, H. C. Hailes, Chem. Commun. 2015, 51, 17225-17228.

[16] D. Könning, W. Hiller, M. Christmann, Org. Lett. 2012, 14, 5258-5261.

[17] C. E. Paul, M. Rodríguez-Mata, E. Busto, I. Lavandera, V. Gotor-Fernández, V. Gotor, S. GarcíaCerrada, J. Mendiola, O. de Frutos, I. Collado, Org. Process Res. Dev. 2014, 18, 788-792.

[18] See, for instance: a) D. J., St. Jean, Jr., C. Yuan, E. A. Bercot, R. Cupples, M. Chen, J. Fretland, C. Hale, R. W. Hungate, R. Komorowski, M. Veniant, M. Wang, X. Zhang, C. Fotsch, J. Med. Chem. 2007, 50, 429-432; b) Y.-J. Wu, H. He, L.-Q. Sun, A. L'Heureux, J. Chen, P. Dextraze, J. E., Starrett, Jr., C. G. Boissard, V. K. Gribkoff, J. Natale, S. I. Dworetzky, J. Med. Chem., 2004, 47, 2887-2896; c) F. C. Y. Chan, G. A. Potter, S. 
E. Barrie, B. P. Haynes, M. G. Rowlands, J. Houghton, M. Jarman, J. Med. Chem. 1996, 39, 3319-3323.

[19] It must be noted that this approach is a simplified study just taking into account the waste generated in the stereoselective amination reaction regarding the amine donor employed. To depict a general overview of the atom and cost efficiencies, more accurate calculations such as $E$ factor should be performed. For more information, see: Y. Ni, D. Holtmann, F Hollmann, ChemCatChem 2014, 6, 930-943.

[20] EATOS: Environmental Assessment Tool for Organic Syntheses, http://www.metzger.chemie.unioldenburg.de/eatos/english.htm, accessed: 05.02.2014. 


\section{FULL PAPER}

But-2-ene-1,4-diamine and But-2-ene-1,4-diol as Donors for Thermodynamically Favored

Transaminase and Alcohol Dehydrogenase-

Catalyzed Processes

Adv. Synth. Catal. Year, Volume, Page - Page

Lía Martínez-Montero, Vicente Gotor, Vicente

Gotor-Fernández,* and Iván Lavandera*

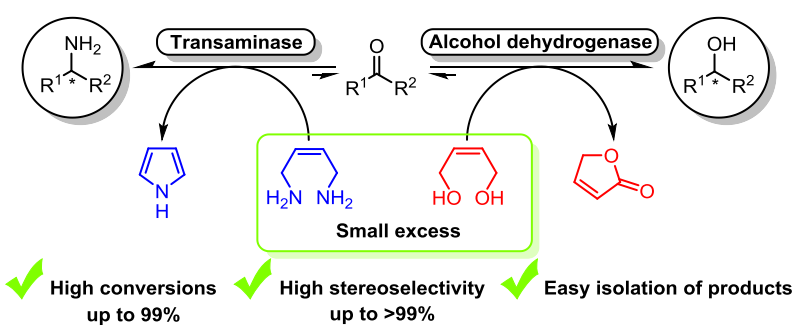

up to $>99 \%$ 